\title{
Empreendedorismo Religioso no Brasil: Os Pastores enquanto Empreendedores
}

Victor Silva Corrêa ${ }^{1}$

Luciana Caldara Estece ${ }^{1}$

${ }^{1}$ Universidade Paulista 


\section{EMPREENDEDORISMO RELIGIOSO NO BRASIL: OS PASTORES ENQUANTO EMPREENDEDORES}

\section{Resumo}

O país tem vivenciado vigorosas transformações de sua estrutura religiosa. Inserem-se, neste contexto, a queda da população católica e o simultâneo e vigoroso crescimento da comunidade evangélica, sobretudo de vertente neopentecostal. Tais modificações encontram na secularização do Estado, isto é, a separação Estado-Igreja, ocorrida no Brasil no século XIX, parte de sua origem explicativa. Com efeito, a secularização acabou por implicar em um contexto religioso diversificado e competitivo, em que agentes religiosos, pastores neopentecostais - aqui de interesse particular -, para sobreviver e se destacar, passaram a atuar como empreendedores. Este artigo, de natureza teórica, insere-se neste contexto. Apropria-se de vertente econômica, a da Escolha Racional da Religião, pouco explorada no Brasil, para ampliar a compreensão das implicações da secularização do Estado sobre a eclosão e evolução do empreendedorismo religioso no país. Ao fazer isto, projeta luzes para a adequação, raramente enfatizada, de perspectiva econômica para o estudo de fenômenos religiosos. Este artigo acaba por edificar novas proposições teóricas.

Palavras-chave: Teoria Racional. Empreendedorismo Religioso. Teoria da Escolha Racional da Religião. Orientação Empreendedora. 


\section{Introdução}

O país tem modificado sua estrutura religiosa. Tal se manifesta pela queda da comunidade católica e pelo simultâneo avigoramento da população evangélica. Só entre 1990 e 2000, esta cresceu a representativa taxa de quase $100 \%$ (Pierucci, 2004b). Atualmente, mais de 42 milhões de pessoas são evangélicas. Se se considerar o período entre 1991 e 2010, o desenvolvimento desta comunidade fornece noção de seu potencial expansivo. Mais de 29 milhões se tornaram protestantes, número 9,4 milhões maior que, por exemplo, a população de Minas Gerais (http://www.ibge.gov.br/home/, recuperado em 4 de abril, 2015).

Este crescimento evidencia a "animada liberdade de [...] associação religiosa" (Pierucci, 1999, p.1) no país. Provoca, por outro, contexto de ampla concorrência entre crescente número de instituições do segmento (Gracino Junior, 2008; Mariano, 2003, 2008, 2013; Passos et al., 2011; Pierucci, 1996, 1999, 2000a, 2008, 2011; Warner, 1993). Ambos remontam à secularização do Estado, oficializada em 1889 pela separação Estado-Igreja, parte de sua origem explicativa (Gracino Júnior, 2008; Mariano, 2003; Pierucci, 1996, 1999, 2000a; Rivera, 2010; Teixeira, 2008). Com efeito, foi a partir dela que se garantiu no Brasil a proteção do pluralismo religioso, a possibilidade de novas denominações ingressarem e conquistarem solidez institucional (Frigério, 2008; Mariano, 2003; Pierucci, 1996, 1999; Teixeira, 2008). Surgiram, aí, expressões religiosas não tradicionais, a exemplo da evangélica, que resultaram e reforçaram o fenômeno (Mariano, 2003, 2013). Atualmente, "o campo religioso brasileiro é o [...] da pluralidade" (Passos; Zorzin \& Rocha, 2011, p. 694). "Liberdade para as religiões é o que [...] não falta por aqui"” (Pierucci, 1996, p. 276).

Neste ambiente diversificado e, sobretudo, competitivo, agentes religiosos, os pastores evangélicos, em particular, passaram a atuar como empreendedores. Seu comportamento derivou da concorrência entre igrejas e da necessidade de luta pela sua sobrevivência (Mariano, 2008, 2013; Pierucci, 1999, 2008). Com efeito, a concorrência franca decorrida do pluralismo acabou resultando em agentes religiosos menos acomodados, mais dinâmicos e bem-dispostos, e em organizações religiosas mais eficientes na mobilização de séquitos, públicos e clientelas (Pierucci, 1999, 2006a, 2006b, 2008). Eles começaram a ser comprometidos, dedicados e militantes (Mariano, 2008; Pierucci, 1999). Abandonaram modos improdutivos e bens impopulares, empregando técnicas mais eficazes, típicas da racionalidade empresarial (Iannaccone, 1995; Mariano, 2008).

Sua capacidade de mobilização é que determina o desempenho de suas igrejas (Gracino Junior, 2008; Marino, 2003, 2008, 2013). Por isto, passaram a: i.) conhecer especificidades do mercado; ii.) adequar produtos e serviços às necessidades dos consumidores; iii.) atrair e recrutar possíveis adeptos/clientes; v.) adotar técnicas publicitárias; vi.) utilizar instrumentos de marketing; vii.) aplicar métodos de gestão típicos da racionalidade econômica; viii.) especializarem-se em nichos de mercado; ix.) apropriar de rádio, TV, música, internet, jornais e literatura; x.) investir no ativismo pastoral; xi.) maximizar recursos líquidos, entre outros (Iannaccone, 1997; Mariano, 2003, 2008).

Ganha relevância, aí, a Abordagem da Escolha Racional da Religião, pouco explorada no Brasil (Iannaccone, 1995, 1997; Iannaccone, Finke \& Stark, 1997; Iannaccone et al., 1995; Finke, 1997; Stark, 1999; Stark, Iannaccone \& Finke, 1996). Edificada nos Estados Unidos a partir da década de 1980, deriva das reflexões de Smith (2003). Baseada em pressupostos
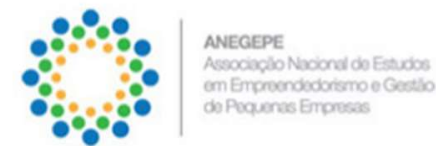

Realizadores:
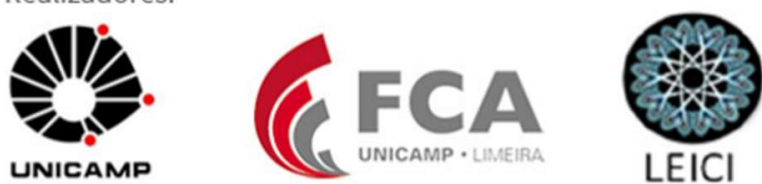
econômicos, projeta luzes sobre os efeitos da secularização do Estado para a liberdade de credo, a oferta, a diversidade e os incentivos dos produtores e consumidores religiosos. Sustenta como ela impulsiona a criação de novos grupos religiosos e o avigoramento da concorrência entre eles. Autores desta vertente salientam que a diversificação da oferta religiosa, possibilitada e impulsionada pela separação Estado-Igreja, eleva o vigor, a capacidade e, sobretudo, a necessidade dos produtores religiosos para mobilizar e satisfazer públicos distintos (Finke, 1997; Frigerio, 2008; Gracino Junior, 2008; Iannaccone et al., 1997; Iannaccone et al., 1998; Mariano, 2003).

Este trabalho, de natureza essencialmente teórica, insere-se justamente neste contexto. Apropria de uma vertente econômica, a da Abordagem da Escolha Racional da Religião, para compreender as implicações da secularização do Brasil sobre a eclosão e evolução do empreendedorismo religioso no país. Ao fazer isto, projetam-se luzes para a importância e adequação, raramente enfatizadas, de uma perspectiva econômica para se analisar fenômenos religiosos. Ao mesmo tempo, enfatiza-se a relevância e apropriação da abordagem da Escolha Racional para se investigar o empreendedorismo religioso brasileiro. Com efeito, a associação entre ambas as temáticas, até então inexplorada na literatura da administração no Brasil, mostrase altamente frutífera. Argumentos da Teoria da Escolha Racional aparentam serem adequados para explicar o contexto religioso no país e o comportamento empreendedor de pastores evangélicos.

A reflexão sobre empreendedorismo e religião ainda não recebeu a atenção necessária por parte da academia (Audretsch et al., 2007, 2013; Dodd \& Gotsis, 2007; Dougherty et al., 2013; Galbraith \& Galbraith, 2007; Griebel et al., 2014; Rietveld \& Burg, 2013). Pesquisas que integram os temas "são surpreendentemente esparsas e inconsistentes" (Dougherty et al., 2013, p. 401). Isto se evidencia no contexto internacional (Dougherty et al., 2013, Finke, 1997; Frigerio, 2008; Iannaccone, 1995, 1997) e brasileiro (Serafim, Martes \& Rodrigues, 2012). Parte desta lacuna se deve à presença de relações complexas, multiníveis e indiretas entre as variáveis (Nwankwo et al., 2012; Nwankwo \& Gbadamosi, 2013; Zelekha et al., 2014). Ao mesmo tempo, observa-se, também, carência de investigações que associam religião e economia (Audretsch et al., 2007). Pesquisas relacionadas a fatores econômicos tipicamente negligenciam as influências da religião (Barro \& McCleary, 2003; Grier, 1997).

$\mathrm{O}$ presente artigo se encontra dividido em quatro partes. A primeira (2.1) enfoca as origens e evoluções das pesquisas sobre religião e economia, e apresenta a Abordagem da Escolha Racional da Religião, derivada delas. A segunda (2.2), por sua vez, reflete sobre a secularização do Estado e sua influência sobre a eclosão do empreendedorismo religioso no Brasil. A terceira (3) apresenta o modelo analítico, e discute a adequação da Teoria da Escolha Racional para explicar a evolução do contexto religioso do país. Finalmente, as considerações finais avançam nas reflexões, sugerindo proposições inéditas.

\section{Fundamentação Teórica: Religião, Economia e Empreendedorismo}

\subsection{Religião e Economia}

A origem da associação entre religião e economia remonta a Adam Smith. O autor foi pioneiro ao salientar a importância da religião em formar economias (Audretsch et al., 2007;

\section{Organizadores:}

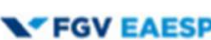

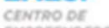

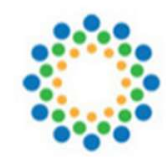

ANEGEPE

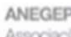

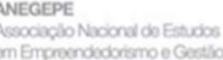

A

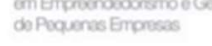

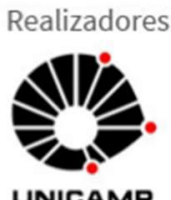

UNICAMP 
Iannaccone, 1998; McCleary, 2008). Em capítulo amplamente ignorado de "A Riqueza das Nações" (Iannaccone, 1998), ele explorou os efeitos da competição e definiu as consequências econômicas das crenças religiosas (Anderson, 1988; Audretsch et al., 2007; Smith, 2003). Ao fazer isto, conectou liberdade religiosa com liberdade econômica, e lançou as bases de duas correntes intelectuais (Anderson, 1988). A primeira se baseia na competição religiosa e na relação estado-igreja como fenômeno de mercado. Nela, aplicou princípios da economia para compreender instituições religiosas. A segunda se fundamenta nas crenças e atividades religiosas como escolhas racionais. Nesta, explicou os incentivos econômicos das opções individuais (Anderson, 1988; McCleary, 2011).

Smith (2003) argumenta que forças de mercado constrangem igrejas da mesma maneira que empresas seculares. Salienta o autor os benefícios da dissociação Estado-igreja (Smith, 2003). Ela permite a pluralidade da fé, a discussão racional sobre crenças e a prática de qualquer religião (McCleary, 2008; Smith, 2003). Ao mesmo tempo, cria mercado aberto, impulsiona a concorrência no segmento (McCleary, 2008, 2011; Pierucci, 2008; Smith, 2003). "Religião, concluiu Smith, é mais vibrante" em estados secularizados (McCleary, 2011, p.16, tradução nossa).

A partir de 1980, diferentes pesquisadores (ver, por exemplo: Finke, 1997; Stark, 1999; Stark, Iannaccone \& Finke, 1996) começaram a criar novo paradigma para a religião (Iannaccone et al., 1997; Iannaccone, Stark \& Finke, 1998; Finke, 1997; Stark, 1999). Denominado "Teoria da Escolha Racional da Religião", baseia-se em pressupostos econômicos do comportamento maximizador, das preferências estáveis e do equilíbrio mercadológico (Stark et al., 1996). Autores desta vertente de raciocínio reinterpretam proposições de Smith, compreendendo a religião como fenômeno de mercado, mercadoria, objeto de escolha e produção (Iannaccone, 1995, 1997; Iannaccone et al., 1997). Eles "tentam levar às últimas consequências [a noção de mercado], equiparando, o máximo possível, mercado econômico e mercado religioso" (Mariano, 2008, p.47). Este seria composto por firmas, produtos e serviços (Gracino Júnior, 2008; Mariano, 2008). Resultaria das decisões de custo-benefício e das ações combinadas de consumidores e produtores religiosos (Iannaccone, 1995, 1997). Distintas reflexões constituem o paradigma. Quatro são de interesse do presente trabalho. São elas: i.) regulação e desregulação religiosas e seus impactos sobre competição de mercado; ii.) pluralismo; iii.) abordagem da oferta versus demanda, e; iv.) escolha racional da religião.

Enquanto regulação estatal implica monopólio religioso e limitadas opções de mercado (Finke, 1997; Frigerio, 2008; Gracino Junior, 2008; Iannaccone et al., 1997; Mariano, 2003, 2008, 2013; Neri et al., 2011; Passos et al., 2011; Pierucci, 1996, 1999, 2000a, 2008, 2011; Rabuske, Santos, Gonçalves \& Traub, 2012; Rivera, 2010; Teixeira, 2008; Warner, 1993), desregulamentação eleva taxas de retorno sobre investimentos (Finke, 1997; Frigério, 2008; Gracino Júnior, 2008; Iannaccone, 1995; Iannaccone et al., 1997; Mariano, 2003, 2008; Warner, 1993). Ao mesmo tempo, estimula a edificação de novas igrejas e o recrudescimento da competitividade entre elas (Finke, 1997; Gracino Júnior, 2008; Iannaccone, 1995, 1997; Iannaccone et al., 1997; Mariano, 2003, 2008; Pierucci, 1999). Fortalece a economia religiosa (Finke, 1997; Frigério, 2008; Gracino Junior, 2008). Resulta daí a dilatação do ativismo militante (Gracino Junior, 2008; Finke, 1997; Frigério, 2008; Iannaccone, 1995; Iannaccone et al., 1997; Iannaccone et al., 1998; Mariano, 2003, 2008; Pierucci, 1999; Warner, 1993) e a elevação no nível de participação dos indivíduos (Finke, 1997; Frigério, 2008; Mariano, 2003).

Organizadores:
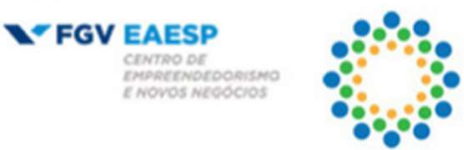

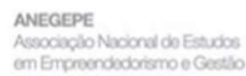

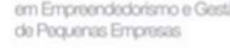

Realizadores:
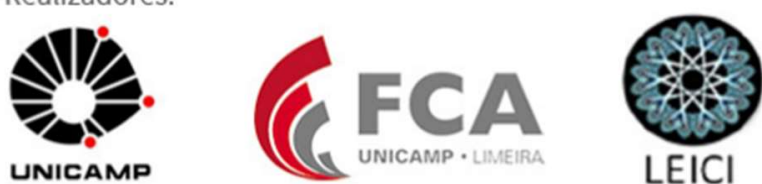
Insere-se, aí, a abordagem da oferta. Salienta que o interesse, o envolvimento e as mudanças mais significativas na religião derivam das variações de sua oferta, não de sua demanda (Finke, 1997; Gracino Junior, 2008; Iannaccone et al., 1997; Mariano, 2003; Pierucci, 1999). Sendo esta relativamente estável (Finke, 1997; Iannaccone et al., 1997), os níveis de participação podem ser mais bem explicados em termos da oferta (Finke, 1997; Mariano, 2008). Com diversificação da oferta, ampliar-se-ia a obrigatoriedade de os produtores religiosos se mobilizarem para atender às necessidades dos públicos (Frigerio, 2008; Gracino Junior, 2008; Iannaccone et al., 1997; Iannaccone et al., 1998; Mariano, 2003). Neste contexto de oferta, portanto, haveria uma elevação nos índices de participação. Com efeito, salientam Iannaccone (1991, 1995, 1997) e Iannaccone, Finke \& Stark (1997) como a participação nas igrejas são mais elevadas nas regiões em que há instituições competindo entre si. Neste contexto, argumenta Warner (1993, p. 1057, tradução nossa) como "não são [as] alternativas disponíveis aos consumidores, mas, os incentivos para os fornecedores encontrarem suas necessidades, que são maximizadas quando a economia está aberta a participantes [...] sem renda garantida" (Warner, 1993, p. 1057, tradução nossa).

Destaca-se, aí, a teoria da escolha racional da religião. Insere-se, na essência de suas reflexões a proposição de que a atuação religiosa das pessoas se baseia no comportamento maximizador e na concepção da religião como contexto no qual os indivíduos promovem ações racionalizadas, incluindo escolhas relacionadas à filiação (Iannaccone, 1995; Pearce et al., 2010; Stark, 1999). Autores propõem que a atuação religiosa é, assim como outras maneiras de ação humana, racional (Hamilton, 2009; Iannaccone et al., 1997; Stark, 1999; Warner, 1993). Comprovações disto podem ser vistas nos fieis e nos pastores. Nos fieis, devido a sua mudança de igreja (Iannaccone, 1995; Warner, 1993). Com efeito, por motivações parcialmente racionais, "pessoas modificam suas preferências religiosas em diferentes maneiras, variando suas taxas de participação, modificando seu caráter ou transformando completamente as religiões" (Iannaccone, 1995, p. 77). Nos pastores, através de seu caráter otimizador. Eles otimizam "membros, recursos, apoio governamental [e] outros determinantes do sucesso institucional" (Iannaccone, 1997, p. 27, tradução nossa). Suas ações "são modeladas como respostas racionais às restrições e oportunidades do mercado religioso" (Iannaccone, 1995, p. 77, tradução nossa).

\begin{tabular}{|l|l|}
\hline \multicolumn{1}{|c|}{ PROPOSIÇÕES } & \multicolumn{1}{|c|}{ AUTORES DE INTERESSE } \\
\hline $\begin{array}{l}\text { Forças de mercado constrangem igrejas da mesma } \\
\text { maneira que empresas seculares; }\end{array}$ & (Iannaccone, 1998; Smith, 2003) \\
\hline $\begin{array}{l}\text { Dissociação Estado-igreja permite: i.) pluralidade da } \\
\text { fé; ii.) discussão racional sobre crenças; iii.) prática de } \\
\text { qualquer religião; iv.) mercado religioso aberto; v.) } \\
\text { avigoramento da concorrência no segmento religioso; }\end{array}$ & (McCleary, 2008; Smith, 2003) \\
\hline $\begin{array}{l}\text { Sem assistência financeira do Estado, em ambiente } \\
\text { com crescente número de produtores, grupos } \\
\text { religiosos dependem unicamente de sua capacidade } \\
\text { em atender às necessidades de seus públicos para } \\
\text { sobreviver; }\end{array}$ & (McCleary, 2011) \\
\hline $\begin{array}{l}\text { Religião como fenômeno de mercado, mercadoria, } \\
\text { objeto de escolha e produção. Composto por firmas, } \\
\text { produtos e serviços, resulta das decisões de custo- } \\
\text { benefício e das ações combinadas de consumidores e e } \\
\text { produtores religiosos; }\end{array}$ & $\begin{array}{l}\text { (Iannaccone, 1995, 1997; Iannaccone et al., 1997; } \\
\text { Iannaccone } \text { et al., 1995; Finke, 1997, Stark, 1999; } \\
\text { Stark } \text { et al., 1996). }\end{array}$ \\
\hline
\end{tabular}


Desregulamentação religiosa: i.) aumenta as taxas de retorno sobre investimento; ii.) a liberdade de credo; iii.) a oferta religiosa; iv.) os incentivos dos produtores e consumidores religiosos; v.) impulsiona a criação de novos grupos e o avigoramento da concorrência entre eles; vi.) fortalece a economia religiosa; vii.) dilata o ativismo militante, e; viii.) eleva os níveis de participação religiosa dos indivíduos;

Oferta religiosa: i.) impulsiona o vigor, a capacidade e, sobretudo, a necessidade dos produtores religiosos para mobilizar e satisfazer públicos; ii.) impulsiona o envolvimento/engajamento dos indivíduos;

Comportamento religioso é racional. Sinais são obtidos nos frequentadores e produtores da religião. Nos primeiros, por meio de sua mobilidade. No segundo, através de seu caráter otimizador.

(Finke, 1997; Frigério, 2008; Gracino Júnior, 2008; Iannaccone, 1995; Iannaccone et al., 1997, 1998; Mariano, 2003, 2008; Warner, 1993)

(Finke, 1997; Iannaccone, 1995, 1997; Iannaccone et al., 1997; Iannaccone et al., 1998; Warner, 1993)

(Hamilton, 2009; Iannaccone, 1995, 1997; Iannaccone et al., 1997; Stark, 1999; Warner, 1993).

Figura 1. Proposições teóricas sobre religião e economia, e os autores de interesse.

Fonte: Elaboração própria

\subsection{Religião e empreendedorismo no Brasil}

A secularização do Estado (Gracino Júnior, 2008; Mariano, 2003; Pierucci, 1996, 1999, 2000a; Rivera, 2010; Teixeira, 2008) instituiu a proteção do pluralismo religioso, isto é, a chance de novas instituições obterem representatividade (Frigério, 2008; Mariano, 2003; Pierucci, 1996, 1999). Surgiram, deste movimento, novas denominações não tradicionais, que reforçaram este contexto (Mariano, 2003, 2013). Atualmente "liberdade para as religiões é o que [...] não falta por aqui" (Pierucci, 1996, p. 276). Culminou, daí ampliação da concorrência entre as igrejas (Mariano, 2008, 2013; Pierucci, 1999, 2008).

Pastores começaram a ser comprometidos (Mariano, 2008; Pierucci, 1999). Eles deixaram de lado bens impopulares, e passaram a utilizar técnicas comuns à racionalidade econômica (Iannaccone, 1995; Mariano, 2008). Em seu comportamento, pastores buscam em dois objetivos fundamentais: conseguir mais recursos e fieis (ver, por exemplo: Hervieu-Léger, 2008; Mariano, 2003; Pierucci, 2008; Prandi, 1996, 1999). Seu "sucesso depende [justamente] de sua capacidade em atrair [...] clientes e gerar renda" (Prandi, 1999, p. 2). Para obter o primeiro, pastores utilizam "inúmeras estratégias e jogos" (Prandi, 1996, p. 74). Com efeito, um “"vendedor', seja de automóveis, seja de salvação, não pode sobreviver [...] sem constante apoio dos 'compradores"” (Iannacconne, 1995, p. 77, tradução nossa). "Uma organização religiosa não pode [...] crescer sem obter recursos" (Iannaccone et al., 1995, p. 2, tradução nossa). Para isto, "mudam a concepção a respeito do dinheiro e dos bens materiais" (Prandi, 2008, p. 164). Ao mesmo tempo, salientam aos fiéis como "o ato de dar dinheiro, com a certeza de que ele vai voltar, acrescido, é um gesto de investidor" (Prandi, 1996, p. 74). Logo, "a prosperidade está aberta a todos. [Só] é preciso que se dê o que se tem para a igreja, quanto mais melhor, de preferência tudo" (Prandi, 1996, p. 74).

Para conseguir mais fieis, clientes (Pierucci, 1999; Prandi, 1999), pastores buscam tirálos de outras religiões (Pierucci, 2006a, 2011; Prandi, 2008). "Converter implica, no fim das contas, 'infidelizar' 'fiéis' das religiões concorrentes. Crescer e se propagar significa [...] atacar [...], e o alvo imediato, no caso brasileiro, é a Igreja Católica” (Pierucci, 2011, p. 474). “A
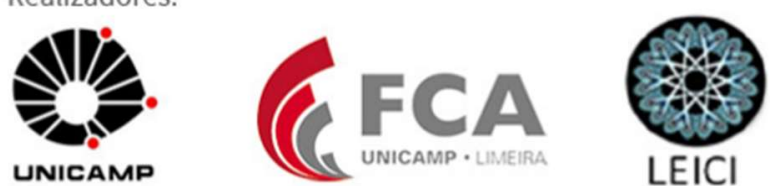
urgência é tal, que o que mais importa é converter: 'ou converte ou converte!'” (Pierucci, 2011, p. 474). "A história recente mostra que [a] estratégia de expansão parte do individual, do miúdo, do pequeno, para, aos poucos, ir se mostrando de forma graúda" (Prandi, 2008, 162).

\begin{tabular}{|c|c|}
\hline PROPOSIÇÕES & AUTORES DE INTERESSE \\
\hline $\begin{array}{l}\text { Secularização do Estado se manifestou, } \\
\text { principalmente, na proteção do pluralismo religioso, a } \\
\text { possibilidade de novas denominações ingressarem e } \\
\text { conquistarem solidez institucional; }\end{array}$ & $\begin{array}{l}\text { (Frigério, 2008; Mariano, 2003, 2013; Pierucci, 1996, } \\
\text { 1999; Teixeira, 2008). }\end{array}$ \\
\hline $\begin{array}{l}\text { Secularização do Estado: i.) impulsionou o surgimento } \\
\text { de expressões religiosas não tradicionais, que } \\
\text { reforçaram o fenômeno; ii.) elevou a competitividade } \\
\text { entre igrejas, aumentando sua luta pela sobrevivência; } \\
\text { iii.) obrigou aos agentes religiosos a necessidade de } \\
\text { serem menos acomodados, mais dinâmicos e bem- } \\
\text { dispostos, e em organizações religiosas mais eficientes } \\
\text { na mobilização de séquitos, públicos e clientelas; }\end{array}$ & $\begin{array}{l}\text { (MARIANO, 2008, 2013; PIERUCCI, 1999, 2006A, } \\
\text { 2006B, 2008) }\end{array}$ \\
\hline $\begin{array}{l}\text { Capacidade mobilizadora dos pastores determina o } \\
\text { desempenho de suas igrejas; }\end{array}$ & $\begin{array}{l}\text { (GRACINO JUNIOR, 2008; MARINO, 2003, 2008, } \\
\text { 2013) }\end{array}$ \\
\hline $\begin{array}{l}\text { Pastores almejam em seu comportamento dois } \\
\text { objetivos principais: i.) conseguir mais recursos, e; ii.) } \\
\text { fieis; }\end{array}$ & $\begin{array}{l}\text { (HERVIEU-LÉGER, 2008; MARIANO, 2003; } \\
\text { PIERUCCI, 2008; PRANDI, 1996, 1999) }\end{array}$ \\
\hline $\begin{array}{l}\text { Para conseguir recursos, pastores: i.) mudam a } \\
\text { concepção a respeito do dinheiro e dos bens materiais, } \\
\text { e; ii.) salientam aos fiéis como o ato de dar dinheiro, } \\
\text { com a certeza de que ele vai voltar, acrescido, é um } \\
\text { gesto de investidor; }\end{array}$ & (Prandi, 1996, 2008) \\
\hline $\begin{array}{l}\text { Para conseguir fieis, pastores subtraem-nos de outras } \\
\text { religiões. O crescimento das igrejas neopentecostais se } \\
\text { dá pela busca da conversão de cada indivíduo. O alvo } \\
\text { imediato são os membros da igreja católica; }\end{array}$ & (Pierucci, 1999, 2006a, 2011; Prandi, 1999, 2008) \\
\hline $\begin{array}{l}\text { Diferentes técnicas de conversão são aplicadas pelos } \\
\text { pastores. Seis são destacadas pela literatura. São elas: } \\
\text { i.) atuar como ativos militantes religiosos; ii.) moldar } \\
\text { produtos e serviços às necessidades dos fieis; iii.) } \\
\text { solucionar dificuldades das pessoas; iv.) copiar bens } \\
\text { de salvação; v.) adotar técnicas publicitárias e } \\
\text { estratégias de marketing, e; vi.) prometer milagres } \\
\text { religiosos. }\end{array}$ & $\begin{array}{l}\text { (Hamilton, 2009; Hervieu-Leger, 2008; Mariano, } \\
\text { 2003, 2008; Pacheco et al., 2007; Pearce et al., 2010; } \\
\text { Pierucci, 1999, 2008; Prandi, 2008) }\end{array}$ \\
\hline
\end{tabular}

Figura 2. Proposições teóricas sobre religião e empreendedorismo no Brasil, e os autores de interesse.

Fonte: Elaboração própria

\section{Modelo analítico: adequação da Abordagem Escolha Racional para o empreendedorismo religioso no Brasil}

É possível observar como a Abordagem da Escolha Racional fornece argumentos considerados capazes de ampliar a atual compreensão sobre a evolução e dinâmica do empreendedorismo religioso no Brasil. A Figura 3, apresentada a seguir, expande a natureza

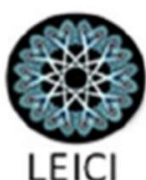


da presente reflexão. Apresenta proposições teóricas de interesse, e associa-as ao contexto religioso brasileiro.

\begin{tabular}{|c|c|}
\hline $\begin{array}{c}\text { Proposições Teóricas } \\
\text { (Abordagem da Escolha Racional da Religião) }\end{array}$ & $\begin{array}{l}\text { Evidências sobre o contexto } \\
\text { religioso brasileiro }\end{array}$ \\
\hline $\begin{array}{l}\text { Dissociação Estado-igreja permite: i.) } \\
\text { pluralidade da fé; ii.) discussão racional sobre } \\
\text { crenças; iii.) prática de qualquer religião; iv.) } \\
\text { mercado religioso aberto; v.) avigoramento da } \\
\text { concorrência no segmento religioso; } \\
\text { (McCleary, 2008; Smith, } 2003\end{array}$ & \\
\hline $\begin{array}{l}\text { Desregulamentação religiosa: i.) aumenta } \\
\text { as taxas de retorno sobre investimento; ii.) a } \\
\text { liberdade de credo; iii.) a oferta religiosa; iv.) os } \\
\text { incentivos dos produtores e consumidores } \\
\text { religiosos; v.) impulsiona a criação de novos grupos } \\
\text { e o avigoramento da concorrência entre eles; vi.) } \\
\text { fortalece a economia religiosa; vii.) dilata o } \\
\text { ativismo militante, e; viii.) eleva os níveis de } \\
\text { participação religiosa dos indivíduos; } \\
\text { (Finke, 1997; Frigério, 2008; Gracino Júnior, 2008; } \\
\text { Iannaccone, 1995; Iannaccone et al., 1997, 1998; } \\
\text { Mariano, 2003, 2008; Warner, 1993) }\end{array}$ & $\begin{array}{l}\text { Secularização do Estado: i.) garantiu a } \\
\text { proteção do pluralismo religioso; ii.) } \\
\text { impulsionou o surgimento de expressões } \\
\text { religiosas não tradicionais, que reforçaram o } \\
\text { fenômeno; iii.) elevou a competitividade entre } \\
\text { igrejas, aumentando sua luta pela } \\
\text { sobrevivência; iv.) obrigou aos agentes } \\
\text { religiosos a necessidade de serem menos } \\
\text { acomodados, mais dinâmicos e bem dispostos, } \\
\text { e em organizações religiosas mais eficientes na } \\
\text { mobilização de séquitos, públicos e clientelas; } \\
\text { (Frigério, 2008; Mariano, 2003, 2008, 2013; }\end{array}$ \\
\hline $\begin{array}{l}\text { Oferta religiosa: i.) impulsiona o vigor, a } \\
\text { capacidade e, sobretudo, a necessidade dos } \\
\text { produtores religiosos para mobilizar e satisfazer } \\
\text { públicos; impulsiona } \\
\text { envolvimento/engajamento dos indivíduos; } \\
\text { (Finke, 1997; Iannaccone, 1995, 1997; Iannaccone } \\
\text { et al., 1997; Iannaccone et al., 1998; Warner, 1993) }\end{array}$ & $\begin{array}{l}\text { P1erucc1, 1996, 1999, 2006a, 2006b, 2008; } \\
\text { Teixeira, 2008) }\end{array}$ \\
\hline $\begin{array}{l}\text { Sem assistência financeira do Estado, em } \\
\text { ambiente com crescente número de produtores, } \\
\text { grupos religiosos dependem unicamente de sua } \\
\text { capacidade em atender às necessidades de seus } \\
\text { públicos para } \\
\text { sobreviver; } \\
(\text { McCleary, 2011) }\end{array}$ & $\begin{array}{l}\text { Capacidade mobilizadora dos pastores } \\
\text { determina o desempenho de suas igrejas; } \\
\text { (Gracino Junior, 2008; Marino, 2003, 2008, } \\
\text { 2013) }\end{array}$ \\
\hline $\begin{array}{l}\text { Comportamento religioso é racional. } \\
\text { Sinais são obtidos nos frequentadores e produtores } \\
\text { da religião. Nos primeiros, por meio de sua } \\
\text { mobilidade. No segundo, através de seu caráter } \\
\text { otimizador. }\end{array}$ & $\begin{array}{l}\text { Pastores almejam em seu } \\
\text { comportamento dois objetivos principais: i.) } \\
\text { conseguir mais recursos, e; ii.) fieis; } \\
\text { (Hervieu-Léger, 2008; Mariano, 2003; Pierucci, } \\
\text { 2008; Prandi, 1996, 1999) }\end{array}$ \\
\hline
\end{tabular}


(Hamilton, 2009; Iannaccone, 1995, 1997; Iannaccone et al., 1997; Stark, 1999; Warner, 1993).

Figura 3. Proposições teóricas sobre abordagem da Escolha Racional da Religião, evidências sobre o contexto religioso brasileiro, e os autores de interesse.

Fonte: Elaboração própria

Note, a partir da Figura 3, como a literatura sobre Escolha Racional fornece argumentos capazes de sustentar a compreensão do contexto religioso no Brasil e sua influência sobre a atual dinâmica do empreendedorismo exercido por pastores evangélicos. Três deles são, aqui, de particular relevância. O primeiro se relaciona às implicações da dissociação Estado-Igreja. Salientam McCleary (2008) e Smith (2003) como ela permite a pluralidade da fé, a prática de qualquer religião. Só na década de 1990, cresceu a representativa taxa de quase $100 \%$ (Pierucci, 2004b). Saltou de pouco mais de 13 milhões de fiéis, em 1991, para cerca de 26 milhões no ano 2000 (Pierucci, 2004a).

Do mesmo modo, salientam autores (ver, por exemplo: Finke, 1997; Iannaccone, 1995; Iannaccone et al., 1997, 1998; Warner, 1993) como a dissociação Estado-Igreja amplia a competitividade no contexto religioso. De fato, foi assim no Brasil. O pluralismo religioso resultou na ampliação da concorrência entre as igrejas. Elas acabaram por revigorar, entre elas, a briga pela sua própria manutenção (Mariano, 2008, 2013; Pierucci, 1999, 2008). Enfatizam Finke (1997), Iannaccone (1995, 1997), Iannaccone et al., (1997), Iannaccone et al., (1998) e Warner (1993) como maior oferta religiosa impulsiona-nos a dilatarem seu ativismo militante. Isto é, seu vigor, sua capacidade e necessidade para mobilizar e satisfazer públicos distintos. Tal fato se evidenciou no Brasil. A elevação da oferta e competitividade religiosa acabou implicando aos agentes do segmento, aos pastores evangélicos, em particular, a necessidade de serem menos acomodados, mais dinâmicos e bem-dispostos (Pierucci, 1999, 2006a, 2006b, 2008). Eles se tornaram comprometidos, dedicados e militantes (Mariano, 2008; Pierucci, 1999). Abandonaram modos improdutivos e bens impopulares, empregando técnicas mais eficazes, típicas da racionalidade empresarial (Mariano, 2008). Passaram a: i.) conhecer especificidades do mercado; ii.) adequar seus produtos e serviços às necessidades dos consumidores; iii.) atrair e recrutar possíveis adeptos/clientes; iv.) adotar técnicas publicitárias; v.) utilizar instrumentos de marketing; vi.) especializarem-se em nichos de mercado, entre outros (Mariano, 2003, 2008).

O segundo argumento, por sua vez, refere-se à sobrevivência das igrejas. Salienta McCleary (2011) como em Estados secularizados grupos dependem unicamente de sua
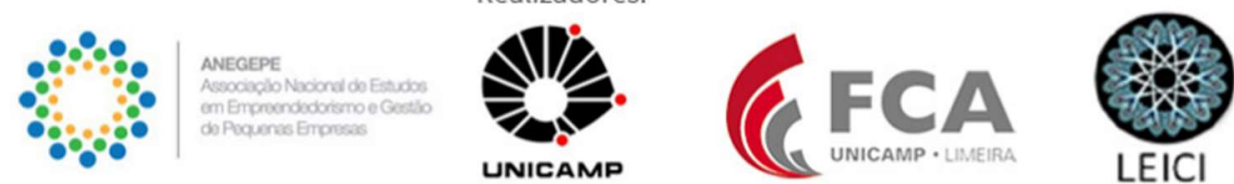
capacidade de agradar aos públicos para se manter no mercado. Tal é observado no país. Mas, há algo mais aí, projetando luzes, ainda, para uma terceira argumentação de considerável relevância teórica. Salientam Hamilton (2009), Iannaccone (1995, 1997), Iannaccone et al., (1997), Stark (1999) e Warner (1993) como o comportamento religioso é racional. Evidências, salientam os autores, podem ser obtidas nos frequentadores e produtores da religião. Nos primeiros, por meio de sua mobilidade. Nos segundos, através de seu comportamento maximizador. No Brasil, ambos demonstram se apropriarem de tais comportamentos. Os frequentadores fazem-na, por exemplo, na escolha religiosa. Sua racionalidade se manifesta na facilidade com que se tornou possível, hoje, mudar de religião (Almeida, 2006; Gracino Junior, 2008; Hervieu-Léger, 2008; Isaia, 2009; Pierucci, 2000a, 2004b, 2006a, 2011; Prandi, 1996, 1999; Teixeira, 2008).

Com efeito, a crença “que se professa já não é aquela que se nasce, mas, que se escolhe" (Prandi, 1999, p. 1). Cerca de 50 milhões de pessoas já abdicou da "identidade religiosa que lhe foi dada como herança, seja para adotar outra que veio a eleger, seja para se juntar à crescente população dos que se definem como 'sem religião"' (Hervieu-Léger, 2008, p. 69). Dois casos ajudam a ilustrar a situação. $\mathrm{O}$ primeiro é o das religiões afro-brasileiras. Anteriormente destinadas à "preservação do patrimônio cultural do negro" (Pierucci, 2006b, p. 117), contam, atualmente, com representativo percentual de seus fiéis formado por brancos. Só no candomblé, são mais de 40\%. "Sua identidade 'africana' é, na verdade, 'africanizada' pela fé, [...] "puramente religiosa"" (Pierucci, 2006b, p. 118). Embora não constitua maioria, o índice pode ser considerado "grande o suficiente para desconstruir demograficamente a velha imagem do candomblé como reduto religioso dos negros" (Pierucci, 2006b, p. 118).

O segundo, de particular importância, é o das igrejas evangélicas. Aproximadamente $70 \%$ de seus membros são convertidos (Rabuske et al., 2012, p. 260). Nelas, o percentual de negros (17\%) é superior ao de pardos (14\%) e brancos (12,6) (Pierucci, 2006b). Se se esmiuçar os dados, chegar-se-á à conclusão de que o número de negros evangélicos é oito vezes superior à soma de todos os negros adeptos às religiões espiritualistas e afro-brasileiras. É possível observar, desta dinâmica, como as pessoas acabam por se basear em critérios racionalizados para a edificação dos seus sistemas de crença (Pierucci, 2006b; Teixeira, 2008).

Já nos produtores religiosos, nos pastores evangélicos, em questão, a racionalidade se expressa, sobretudo, em seu comportamento maximizador. Eles buscam nele dois objetivos principais: conseguir mais recursos e fieis (ver, por exemplo: Hervieu-Léger, 2008; Mariano, 2003; Pierucci, 2008; Prandi, 1996, 1999). Seu "sucesso depende [justamente] de sua capacidade em atrair [...] clientes e gerar renda" (Prandi, 1999, p. 2). Para obter o primeiro, pastores "mudam a concepção a respeito do dinheiro e dos bens materiais" (Prandi, 2008, p. 164). Para conseguir mais seguidores, clientes (Pierucci, 1999; Prandi, 1999), pastores subtraem-nos de outras religiões (Pierucci, 2006a, 2011; Prandi, 2008). (Prandi, 2008, 162). Diferentes técnicas de persuasão e conversão são aí aplicadas (Hamilton, 2009; Hervieu-Leger, 2008; Mariano, 2003, 2008; Pacheco et al., 2007; Pearce et al., 2010; Pierucci, 1999, 2008; Prandi, 2008).

\section{Considerações Finais}


Este ensaio buscou compreender o fenômeno do empreendedorismo religioso no Brasil, o pastor como empreendedor, em particular. Buscou-se isto a partir de uma vertente econômica, a da Teoria da Escolha Racional da Religião, pouco explorada no país. Ao fazê-lo, projetou-se luzes para a importância e adequação, raramente enfatizada, de uma abordagem econômica para se compreender fenômenos religiosos. Ao mesmo tempo, enfatizou-se a relevância e apropriação da abordagem da Escolha Racional para se analisar o empreendedorismo religioso brasileiro. Com efeito, a associação entre ambas as temáticas, até então inexplorada na literatura da administração no Brasil, mostrou-se altamente frutífera. Argumentos da Teoria da Escolha Racional ajudaram a explicar a evolução do contexto religioso no país e o comportamento empreendedor de pastores evangélicos. Diferentes reflexões derivaram daí.

A primeira se relaciona à dissociação Estado-Igreja. Como salientado por McCleary (2008) e Smith (2003), ela permite a pluralidade da fé e a prática de qualquer religião. No Brasil, contribuiu para a criação e consolidação da comunidade evangélica, atualmente em crescimento. A segunda, por sua vez, refere-se à influência da desregulamentação religiosa sobre a concorrência no segmento (Finke, 1997; Iannaccone, 1995; Iannaccone et al., 1997, 1998; Warner, 1993). Com efeito, a partir dela se observou no Brasil a elevação da competitividade entre igrejas, sobretudo evangélicas (Mariano, 2008, 2013; Pierucci, 1999, 2008). Elas avigoraram entre si a disputa pela própria sobrevivência. A terceira se relaciona à sua influência sobre produtores religiosos. Tal como salientado por Finke (1997), Iannaccone (1995, 1997), Iannaccone et al., (1997), Iannaccone et al., (1998) e Warner (1993), pluralidade religiosa impulsiona seu ativismo militante. Assim ocorreu no país. Pastores evangélicos se tornaram, devido à elevação da oferta e da competitividade religiosas, menos acomodados, mais dinâmicos e bem-dispostos (Pierucci, 1999, 2006a, 2006b, 2008). A quarta se associa à sobrevivência das igrejas. Como argumentado por McCleary (2011), é justamente a habilidade de mobilização dos pastores que influencia a performance de suas igrejas.

Finalmente, a quinta, de particular relevância, relaciona-se ao comportamento racionalizado (Hamilton, 2009; Iannaccone, 1995, 1997; Iannaccone et al., 1997; Stark, 1999; Warner, 1993). Frequentadores religiosos e pastores evangélicos aparentam se fundamentarem nele (Hervieu-Léger, 2008; Mariano, 2003; Pierucci, 1999, 2006a 2008, 2011; Prandi, 1996, 1999). Os primeiros através da escolha religiosa. Frequentadores se baseiam em critérios racionalizados, não adscritos, para a construção de seus sistemas de fé (Pierucci, 2006b; Teixeira, 2008). Os segundos por meio do seu caráter maximizador. Este se evidencia na busca dos pastores por mais recursos e fieis. Esta é uma importante constatação. Nenhum estudo da administração no Brasil projetou luzes até o momento sobre o comportamento racionalizado e econômico de pastores evangélicos. Nem, tampouco, salientou a natureza de seu comportamento empreendedor, apropriando-se de vertente econômica para sustentar a reflexão.

Novos estudos teóricos e empíricos se demonstram necessários. Eles devem apropriar da Abordagem da Escolha Racional da Religião para avançar em reflexões, aqui suscitadas, sobre a secularização do Estado brasileiro e sua repercussão sobre a propensão empreendedora de pastores evangélicos. Como temas de futuras pesquisas, sugerem-se investigações capazes de: i.) analisar o comportamento empreendedor dos pastores, identificando diferentes fatores econômicos que influenciam sua manifestação; ii.) pesquisar a competitividade entre igrejas evangélicas, salientando práticas e comportamentos que diferenciam-nas no mercado; iii.) investigar o comportamento maximizador de pastores e frequentadores evangélicos, ampliando
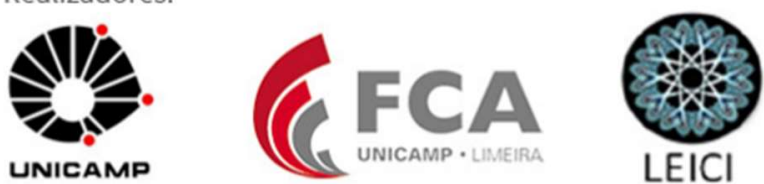
argumentos teóricos associados à racionalidade religiosa; iv.) inquirir como práticas econômicas e racionalizadas influenciam o desempenho congregacional, robustecendo argumentos associados ao desenvolvimento bem-sucedido de igrejas, entre outras.

As reflexões aqui salientadas sinalizam para a relevância deste ensaio. Além de integrar proposições sobre religião e empreendedorismo, hoje surpreendentemente esparsas e inconsistentes (Dougherty et al., 2013), associou-as a uma vertente econômica, a da Abordagem da Escolha Racional da Religião, inexplorada no campo da administração no país. Ao mesmo tempo, empregou tais proposições na análise da eclosão e evolução do empreendedorismo religioso no Brasil, de pastores como empreendedores, em particular. Embora emergentes, caracterizados por amplo crescimento, pastores compreendidos como empreendedores são pouco investigados no país. Ao fazer isto, este trabalho projetou luzes para reflexões, inéditas na literatura, sobre o comportamento empreendedor, econômico e racionalizado de pastores evangélicos, salientando dimensões que influenciam no desenvolvimento bem-sucedido de seus empreendimentos. Neste sentido, avançou em território virgem. Há, certamente, possibilidades para novas reflexões e descobertas. As inferências aqui realizadas funcionariam como estímulo para análises mais amplas e variadas sobre o fenômeno do empreendedorismo religioso brasileiro à luz de dada vertente econômica.

\section{Referências}

Almeida, R. (2006). A expansão pentecostal: circulação e flexibilidade. In F. Teixeira $\&$ R. Menezes (Orgs.), As religiões no Brasil: continuidades e rupturas (Cap. 7, pp. 111-122). Petrópolis: Vozes.

Anderson, G. M. (1988). Mr. Smith and the Preachers: The Economics of Religion in the Wealth of Nations. Journal of Political Economy, 96(5), 1066-1088.

Audretsch, D. B., Boente, W., \& Tamvada, J. P. (2007). Religion and Entrepreneurship. Jena economic research papers, 75, 1-27.

Audretsch, D. B., Boente, W., \& Tamvada, J. P. (2013). Religion, social class, and entrepreneurial choice. Journal of Business Venturing, 28, 774-789.

Barro, R. J., \& McCleary, R. M. (2003). Religion and Economic Growth across Countries. American Sociological Review, 68(5), 760-781

Camargo, C. P. F. (1973). Católicos, Protestantes, Espíritas. Petrópolis: Vozes.

Dodd, S. D. \& Gotsis, G. (2007). An Examination of the Inter-relationships between Entrepreneurship and Religion.

Dougherty, K. D., Griebel, J., Neubert, M. J., \& Park, J. Z. (2013). A Religious Profile of American Entrepreneurs. Journal for the Scientific Study of Religion, 52(2), 401-409.

Finke, R. (1997). The Consequences of Religious Competition: supply-side explanations for religious change. In L. A. Young (Ed.), Rational Choice Theory and Religion (Cap. 3, pp. 45-63). Routledge.

Frigerio, A. (2008). O paradigma da escolha racional: mercado regulado e pluralismo religioso. Tempo Social, revista de sociologia da USP, 20(2), 17-39.

Galbraith, C. S., \& Galbraith, D. M. (2007). An empirical note on entrepreneurial activity, intrinsic religiosity and economic growth. Journal of Enterprising Communities: People and Places in the Global Economy, 1(2), 188-201.
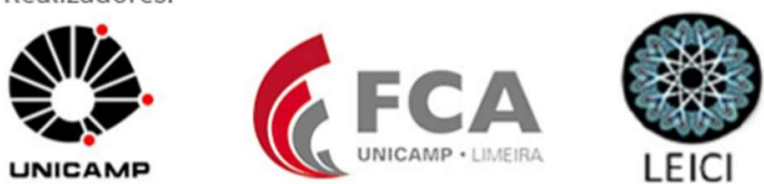
Gracino Júnior, P. (2008). Dos interesses weberianos dos sociólogos da religião: um olhar perspectivo sobre as interpretações do pentecostalismo no Brasil. Horizonte, 6(12), 6992.

Griebel, J. M., Park, J. Z., \& Neubert, M. J. (2014). Faith and Work: An Exploratory Study of Religious Entrepreneurs. Religions, 5(3), 780-800.

Grier, R. (1997). The Effect of Religion on Economic Development: A Cross National Study of 63 Former Colonies. Kyklos, 50(1), 47-62.

Hamilton, M. (2009). Rational Choice Theory: A critique. In O, B, Clarke (Ed.), The Oxford Handbook of The Sociology of Religion (pp.116-133). Oxford University Press: New York

Hervieu-Léger, D. (2008). O peregrino e o convertido: a religião em movimento. Petrópolis: Vozes.

Iannaccone, L. (1994). Why Strict Churches are Strong. American Journal of Sociology, 99(5), 1180-1211.

Iannaccone, L. (1995). Voodoo Economics? Reviewing the Rational Choice Approach to Religion. Journal for the Scientific Study of Religion, 34(1), 76-88.

Iannaccone, L. (1997). Rational Choice: framework for the scientific study of religion. In L. A. Young (Ed.), Rational Choice Theory and Religion (Cap. 2, pp. 25-44). Routledge.

Iannaccone, L. (1998). Introduction to the Economics of Religion. Journal of Economic Literature, 36(3), 1465-1495.

Iannaccone, L., Finke, R., \& Stark, R. (1997). Deregulating religion: the economics of church and state. Economic Inquiry, 35(2), 350-364.

Iannaccone, L., Olson, D. V.A., \& Stark, R. (1995). Religious Resources and Church Growth. Social Forces, 74(2), 705-731.

Iannaccone, L., Stark, R., \& Finke, R. (1998). Rationality and the "Religious Mind". Economic Inquiry, 36(3), 373-389.

Isaia, A. C. (2009). O campo religioso brasileiro e suas transformações históricas. Revista Brasileira de História das Religiões, (3), 95-105.

Mariano, R. (2003). Efeitos da secularização do Estado, do pluralismo e do mercado religiosos sobre as igrejas pentecostais. Civitas - Revista de Ciências Sociais, 3(1), 111-125.

Mariano R. (2008). Usos e limites da teoria da escolha racional da religião. Tempo Social, revista de sociologia da USP, 20(2), 41-66.

Mariano, R. (2013). Antônio Flávio Pierucci: sociólogo materialista da religião. Revista Brasileira de Ciências Sociais, 28(81), 7-16.

McCleary, R. M. (2008). Religion and Economic Development.

McCleary, R. M. (2011). The Oxford Handbook of the Economics of Religion (Cap. 1, pp. 3-38). New York: Oxford University Press

Neri, M. C., Carvalhaes, L., \& Monte, S. R. S. (2011). Novo Mapa das Religiões (Relatório de Pesquisa/2011), São Paulo, SP, Centro de Políticas Sociais, Fundação Getúlio Vargas.

Nwankwo, S. \& Gbadamosi, A. (2013). Faith and entrepreneurship among the British African-Caribbean: Intersections between religious and entrepreneurial value. Journal of Small Business and Enterprise Development, 20(3), 618-633. 
Nwankwo, S., Gbadamosi, A., \& Ojo, S. (2012). Religion, Spirituality and Entrepreneurship: The church as entrepreneurial space among British Africans. Society and Business Review, 7(2), 149-167.

Pacheco, E. T., Ribeiro da Silva, S., \& Ribeiro, R. G. (2007). "Eu era do mundo": tranformações do auto-conceito na conversão pentecostal. Psicologia: Teoria e Pesquisa, 24(1), 5362.

Passos, M., Zorzin, P. L. G., \& Rocha, D. (2011). O que (não) dizem os números - para além das estatísticas sobre o "Novo Mapa das Religiões Brasileiro". Horizonte, 9(23), 690-714.

Pearce, J. A., Fritz, D. A., \& Davis, P. S. (2010). Entrepreneurial Orientation and the Performance of Religion Congregations as Predicted by Rational Choice Theory. Entrepreneurship Theory and Practice, 34(1), 219-248.

Pierucci, A. F. (1996). Liberdade de cultos na sociedade de serviços. In A. F. Pierucci \& R. Prandi (Eds.), A realidade social das religiões no Brasil (Cap. 12, pp. 275-286). Hucitec: São Paulo

Pierucci, A. F. (1999, dezembro 26). Fim da união Estado-Igreja ampliou oferta de religiões. Folha de São Paulo, Caderno Especial.

Pierucci, A. F. (2000a). As religiões no Brasil. In J. Gaarder, V. Hellern, \& H. Notaker (Eds.), O Livro das Religiões (pp. 281-302). São Paulo: Companhia das Letras

Pierucci, A. F. (2004a). "Bye bye, Brasil" - o declínio das religiões tradicionais no Censo 2000. Estudos Avançados, 18(52), 17-28.

Pierucci, A. F. (2004b). Secularização e declínio do catolicismo. In B. M. Souza, de. \& L. M. S. Martinho (Orgs.), Sociologia da religião e mudança social: católicos, protestantes e novos movimentos religiosos no Brasil (Cap. 1, pp. 13-21). São Paulo: Paulus

Pierucci, A. F. (2006a). Ciências sociais e religião: a religião como ruptura. In F. Teixeira, \& R. Menezes (Orgs.), As religiões no Brasil: continuidades e rupturas (Cap. 1, pp. 17-34). Petrópolis: Vozes 111-127.

Pierucci, A. F. (2006b). Religião como solvente - uma aula. Novos Estudos - CEBRAP, 75,

Pierucci, A. F. (2008). De olho na modernidade religiosa. Tempo Social, revista de sociologia da USP, 20(2), 9-16.

Pierucci, A. F. (2011). Religiões no Brasil. In A. Botelho, \& L. M. Schwarcz (Orgs.), Agenda Brasileira: temas de uma sociedade em mudança (Cap. 41, pp. 470-479). São Paulo: Companhia das Letras

Prandi, R. (1996). Religião Paga, Conversão e Serviço. Novos Estudos - CEBRAP, 45, 6577.

Prandi, R. (1999, dezembro 26). Religião não é mais herança, mas opção. Folha de São Paulo, Caderno Especial.

Prandi, R. (2008). Converter indivíduos, mudar culturas. Tempo Social, revista de sociologia da USP, 20(2), 155-172.

Rabuske, I. J., Santos, P. L., dos, Gonçalves, H. A., \& Traub, L. (2012). Evangélicos brasileiros: quem são, de onde vieram e no que acreditam? Revista Brasileira de História das Religiões, 4(12), 255-267.

Rietveld, C. A., \& Burg, E. V. (2013). Religious Beliefs and Entrepreneurship Among Dutch Protestants.

Rivera, P. B. (2010). Pluralismo Religioso e Secularização: Pentecostais na periferia da cidade de São Bernardo do Campo no Brasil. Revista de Estudos da Religião, 50-76. 
Serafim, M. C., Martes, A. C. B., \& Rodriguez, C. L. (2012). "Segurando na mão de Deus": organizações religiosas e apoio ao empreendedorismo. Revista de Administração de Empresas, 52(2), 217-231.

Smith, A. (2003). A riqueza das nações. São Paulo: Record

Stark, R. (1999). Micro Foundations of Religion: A Revised Theory. Sociological Theory, 17(3), 264-289.

Stark. R., Iannaccone, L. R., \& Finke, R. (1996). Religion, Science, and Rationality. The American Economic Review, 86(2), 433-437.

Teixeira, F. (2008). Apresentação. In D. Hervieu-Léger, O peregrino e o convertido: a religião em movimento (pp. 7-13). Petrópolis: Vozes.

Warner, R. S. (1993). Work in Progress Toward a New Paradigm for the Sociological Study of Religion in the United States. American Journal of Sociology, 98(5), 1044-1093.

Zelekha, Y., Avnimelech, G., \& Sharabi, E. (2014). Religious institutions and entrepreneurship. Small Business Economics, 42, 747-767. 